\title{
(RE)ESCREVER(SE) O PAI - DIAS PERDIDOS, DE LÚCIO CARDOSO'
}

\author{
Marina Couto RIBEIRO \\ Universidade Estadual de Montes Claros \\ ninacoutoo@gmail.com \\ Fábio Figueiredo CAMARGO \\ Universidade Estadual de Montes Claros \\ fcamargo3@uol.com.br
}

\begin{abstract}
Resumo: A relação estabelecida entre a vida e a escrita sempre foi muito discutida no meio literário. Em alguns casos, acreditava-se ser apenas o texto 0 objeto de pesquisa importante para o desenvolvimento da crítica. Em outros, biografias eram analisadas, fazendo da memória a principal marca da escrita e uma forma de reconstrução da vida, uma vez que a língua permite que o autor possa, através das palavras, (re)inventar a memória e fazer de sua obra um reflexo, mesmo que nebuloso, da imagem que se constrói do real. Este artigo pretende destacar alguns pontos comuns entre Dias Perdidos, de Lúcio Cardoso, e a vida do próprio autor, pois se pode perceber que as obras deste refletem passagens de sua vida, principalmente no que diz respeito às questões relacionadas à paternidade, traçando um paralelo entre a relação estabelecida entre ele mesmo e seu pai, Joaquim Lúcio Cardoso, e a relação entre Sílvio e Jaques, personagens do romance. Para comprovar essa relação vida/obra, utilizaremos os estudos de Andréa de Paula Xavier Vilela e Ruth Silviano Brandão como embasamento teórico, além de trechos de correspondências do próprio Lúcio Cardoso coletadas em seu Acervo, contido na Fundação Casa de Rui Barbosa, no Rio de Janeiro.
\end{abstract}

Palavras-Chave: Literatura brasileira. Literatura de Minas Gerais. Lúcio Cardoso. Autobiografia ficcional. Paternidade.

Abstract: The relationship between life and writing has always been much discussed in literary circles. In some cases, the text was the only object of research important for the development of criticism. In other cases, biographies were analyzed, making memory the main trademark of writing and a way of reconstructing life, since through words, language allows the author to (re)invent memory and make his work a reflection, even if obscure, of the image we build of reality. This article seeks to highlight some commonalities between Lúcio Cardoso's Dias perdidos and his own life, because we are able to perceive that his works reflect passages from his life, especially regarding issues related to paternity, drawing a parallel between the relationship between himself and his father, Joaquim Lúcio Cardoso, and the relationship between the novel's characters, Silvio and Jaques. To demonstrate this life-work relationship, we use as theoretical support studies by Andrea de Paula Xavier Vilela and Ruth Silviano Brandão as well as excerpts from the correspondence 
of Lúcio Cardoso himself found in his Collection, maintained in Casa de Rui Barbosa Foundation in Rio de Janeiro.

Key words: Brazilian literature. Minas Gerais Literature. Lúcio Cardoso. Fictional autobiography. Paternity.

Só as pessoas realmente fortes podem viver na realidade definitiva das coisas; quase todo mundo vaga numa atmosfera morna de fantasia.

Lúcio Cardoso

Lúcio Cardoso - descrito por Raquel de Queiroz como "um jovem arcanjo rebelde", um homem "muito louco e inteiramente mergulhado em sua obra" no documentário Lúcio Cardoso: inventor de totalidades existenciaisii - foi um escritor mineiro que seguiu a vertente do romance psicológico, voltando-se para a intimidade das suas criaturas. Seus romances possuem um caráter denso e fogem do cenário de paisagens ensolaradas mineiras, chegando ao subterrâneo e à escuridão, nos quais o escritor nos apresenta personagens envoltas em tabus e contratos sociais que as levam ao fracasso. A tragédia humana aparece, então, como um dos principais temas cardosianos e é explorada com um tom alucinatório, carregado de paixão, melancolia, angústia, erotismo, solidão e desespero.

Ruth Silviano Brandão apresenta o escritor Lúcio Cardoso como um 'príncipe esfarrapado', constituído por sua própria fragmentação e marcado pelo "sinal que não perdoa" (BRANDÃO, 2007, p. 38). A autora aproxima a vida do autor a seus romances, afirmando que, embora não haja uma "relação de causa e efeito" entre vida e obra, há uma grande proximidade entre elas:

Hoje, cada vez mais, a leitura que se faz da ficção literária leva em conta a vida daquele que escreve, não estabelecendo uma relação de causa e efeito entre ambas, mas considerando a própria vida como um texto tecido de palavras, linguagem que constitui o sujeito atravessado por elas que, por sua vez, dizem deles. (BRANDÃO, 1998, p.26) 
Tal aproximação pode ser comprovada por palavras do próprio Lúcio Cardoso em um artigo escrito sobre as obras de William Faulkner:

Do nada só se tira o nada - e o criador tira sua criação, qualquer que seja ela, do seu fermento intimo (sic.), de suas contradições, de sua ância (sic.) de entender e impor ao mundo, um conjunto de valores que representem uma imagem de sua força interior. (CARDOSO, s/d, p. $1^{\mathrm{iii}}$ ).

Dessa forma, percebemos que, para Lúcio Cardoso, a escrita é uma forma de se reinventar, uma maneira de dizer de si sem se comprometer com a verdade, podendo, assim, utilizar-se tanto do imaginário quanto da memória. Escrever seria, portanto, fragmentar o sujeito escritor, fazendo dele próprio de suas emoções, sentimentos e dúvidas perante o mundo - sua matériaprima, matéria essa que envolve processos de reconstrução, uma vez que a escrita dá ao indivíduo o poder de intervir, de recriar. A reconstrução de si mesmo passa, então, a ser um dos objetivos da escrita para Lúcio Cardoso, que se utiliza do discurso para se reafirmar e se realizar:

Sabemos que a escrita vai na frente de quem escreve, tem alguma coisa de oracular, que é o outro nome do desejo: desejo de realização do que há de mais genuíno no sujeito: uma nova ordem, um mundo que se possa abrir para fora do instituído, dos estreitos limites do senso-comum, para além das representações vigentes, problematizando o conceito de normalidade, criando um novo espaço de construção de saber e de invenção da vida. Sua saída [de Lúcio Cardoso] talvez esteja em uma escrita que disse mais do que o escritor supunha, pois o ato de escrever ultrapassa aquele que escreve, abre outras fronteiras, franqueia um espaço para que o desejo fale, mesmo que essa voz não se faça reconhecer facilmente. (BRANDÃO, 2007, p. 36)

O escritor Lúcio Cardoso parece ter levado essa questão a sério em sua escrita. Uma escrita que fala mais do que parece querer dizer; que, embora cheia de lacunas, traga o escritor para dentro de seu redemoinho de paixões insuspeitas, fracassos e desilusões para com as estruturas sociais armadas pelas famílias tradicionais de Minas Gerais. Seu desejo torna-se, portanto, visível em suas narrativas, principalmente no romance Dias perdidos, que foi considerado por Mario Carelli (1988) como um "romance autobiográfico". Cássia dos Santos, pesquisadora da obra de Lúcio Cardoso, também considera o livro como sendo "de cunho autobiográfico, [que] denunciava o 
trabalho de um escritor mais maduro, apresentando temas e motivos que seriam caros ao futuro autor de Inácio e da Crônica da casa assassinada" (SANTOS, 2001, p. 93).

O romance Dias perdidos, reconhecido por Fernando Sabino - até então como a obra-prima de Lúcio Cardoso em carta ao escritor datada de 1ํ de dezembro de 1943, conta a história de Sílvio, um personagem transtornado e marcado pela desarmonia e melancolia causadas, dentre outros fatores, pela falta do pai. O pai de Sílvio, Jaques - variação francesa de "Joaquim" (vale ressaltar que Joaquim é o nome do pai biológico de Lúcio Cardoso) -, é apresentado na obra como um homem desprendido de qualquer vínculo familiar, um viajante, aventureiro, preso a sentimentos efêmeros que se perdem em suas buscas por realizações pessoais. De acordo com o narrador em terceira pessoa: "Na realidade ele não amava senão o que era exatamente efêmero" (CARDOSO, 1980, p.10). Jaques se mostra, então, como um pai fracassado, desprovido de qualquer possibilidade de exercer sua função paterna, já que, "secretamente Jaques odiava o matrimônio" (CARDOSO, 1980, p.10). Ciente de seu fracasso como elemento de autoridade familiar e movido pela busca incessante de realização, o patriarca abandona sua família, deixando para Sílvio um ambiente desestruturado e melancólico.

Após a partida de Jaques, Clara, ainda apaixonada pelo homem charmoso e sedutor que o marido fora, passa a culpar o filho por sua solidão, deixando-o à margem de sua presença. Assim, Sílvio passa a infância sem referenciais paternos e tenta suprir a falta do pai delegando a outros essa função. Essa busca torna Sílvio um indivíduo transtornado e desacreditado de si mesmo, o que, mais tarde, resultará em um adulto fracassado, vencido por traições e sentimentos de culpa.

A obra une com esmero os 'fantasmas' reais e fictícios do autor empírico. Fernando Sabino, na carta supracitada a Lúcio Cardoso, afirma ser essa a obra que mais demonstra a habilidade do nosso escritor com as palavras. ${ }^{\text {iv }}$ Vejamos: 
As palavras do seu livro me impressionaram muito, como você está sabendo jogar com elas, como você está conseguindo dizer com elas o que tem a dizer! Tudo se ajusta perfeitamente, o conteúdo, a forma, esteticamente acho que "Dias Perdidos" é admirável. Nada ficou por dizer, nem um desvio de pensamento, nem uma daquelas desorientações tão comuns, o autor alucinado pelo turbilhão de palavras que vêm brotando sem parar, nada disso. Há uma harmonia linda no seu livro, principalmente nas duas primeiras partes, por onde a nossa emoção escorrega, e a gente sofre impulsivamente uma a uma de suas palavras. [...] Achei seu livro admirável, sob todos os aspectos! [...] Com franqueza, acho 'Dias Perdidos' uma obra prima, acho que existem muito poucos livros onde o autor se sinta tão senhor de si. [...] A serenidade com que a gente tem a impressão que você conseguiu criar o livro é realmente admirável. Ele existia, então você escreveu. Contando com todos os elementos, com todas as qualidades, com todos os recursos, tudo ajustado, certo, nada faltando ou sobrando. Uma perfeição de equilíbrio no movimento, harmonia na concepção. (SABINO, 1943, s/p.)

O interesse de Fernando Sabino é admirável, pois implica ir contra o pensamento de Mario de Andrade, seu mentor à época, que, em carta a Sabino, havia tecido comentários pouco elogiosos à literatura de Lúcio Cardoso, devido ao fato de o escritor mineiro estar muito envolvido com a questão católica naqueles idos dos anos 1940. No entanto, deve-se destacar que Sabino, não contente em denominar Dias perdidos de obra-prima, afirma que Lúcio Cardoso exibe uma serenidade ao escrever o texto, "é senhor de si" nesse livro. Do mesmo modo, não deixa de ser instigante o fato de o autor de O encontro marcado considerar que o livro "existia", apontando para um texto que fermenta dentro do sujeito escritor até o momento de sua produção, produção esta que parece brotar sem arestas, na qual nada falta nem sobra. Assim, ainda segundo Sabino, percebe-se na linguagem de Dias perdidos uma musicalidade e harmonia intensas que completam com maestria a denúncia da crueldade mascarada de uma sociedade, de uma família em ruínas, tema recorrente nas obras cardosianas.

Lúcio Cardoso, assim como Sílvio, também possui um pai ausente que aparece sempre como um vulto, enevoado em histórias de viagens sempre fracassadas. Walmir Ayala, em biografia não publicada de Lúcio Cardoso, apresenta o pai do autor de Crônica da casa assassinada como um viajante transformado em personagem do escritor: 
Seu pai, Joaquim Lúcio Cardoso, era um andarilho, fundador de cidades, com três anos de engenharia e o espírito da aventura - este homem seria o personagem principal do primeiro romance de Lúcio Cardoso, Maleita (sic.), publicado em 1934. (AYALA, s/d, p. 01).

Essa criação do pai de Cardoso como personagem de seus romances já está destacada nos trabalhos de Cássia dos Santos, Mario Carelli, José Marco Pessoa (1998) e Andrea Xavier Vilela (2007). Nesses textos, não mais Maleita é objeto de análise, mas Dias perdidos. Isso vem ao encontro do que queremos postular neste artigo: o pai de Lúcio Cardoso é um dos sujeitos reais, transfigurados pelo escritor em seus romances e novelas, o que aponta para uma relação bastante coesa entre biografia e escrita.

Conforme Cássia dos Santos, "somente em 1967, com a publicação de Por onde andou meu coração, o primeiro livro de memórias de Maria Helena Cardoso, que o público leitor pôde constatar o quanto de autobiográfico havia no quarto romance do ficcionista" (SANTOS, 2001, p. 108). Isso confirma a asserção do próprio Lúcio Cardoso de que um escritor não tira nada do nada; sua escrita, pode-se entender de seu raciocínio sobre Faulkner, é parte dele, sua vida se escreve conjuntamente com seu texto e, no caso de Lúcio, seu pai é tomado e fragmentado em diversos personagens, interessando-nos neste artigo a relação de Jaques com seu filho Sílvio, personagens de Dias perdidos.

Em uma carta para Lúcio Cardoso, Manuel Bandeira afirma que as personagens do escritor mineiro nada mais são do que uma descrição do próprio Lúcio: "As suas personagens são como você que é um homem de sensibilidade aguda e torturada." (BANDEIRA, 1935, p. 01). Tal "sensibilidade torturada" pode ser vista como consequência da imagem fracassada que o pai de Lúcio Cardoso representa, pois a falta da figura paterna e o ideal de paternidade fracassado podem implicar a diferença com a qual sujeito deve operar em busca de meios para se afirmar ante a sociedade. No caso de Lúcio Cardoso, acreditamos que esse meio possa ser a escrita sobre seu pai, na qual ele também se implica, ao se autorrepresentar inscrevendo-se em seu próprio texto. 
A paternidade é uma questão cultural e é responsável pela organização da sociedade. Para Freud (1999), a imagem que o filho constrói do pai está relacionada aos poderes excessivos e à desconfiança, a qual está intimamente ligada à admiração que o filho possui pelo pai. Sendo assim, a figura paterna é alvo de ódio - uma vez que representa um obstáculo aos anseios de poder e aos desejos sexuais - e de admiração - pois sua ausência causa melancolia e desequilíbrio pessoal. Dessa forma, a ausência da figura paterna é elemento decisivo para a criação do escritor Lúcio Cardoso, pois o autor transfere para seus romances o que chamamos de "escrita da orfandade", que consiste em uma busca pela própria origem, uma tentativa de recuperar algo que foi perdido no passado.

Assim, personagens fortemente marcados pela ausência da autoridade paterna são recorrentes nos romances cardosianos. Não é diferente com o "romance autobiográfico" Dias Perdidos, pois o personagem Sílvio, por ser isento da figura de autoridade paterna, torna-se um sujeito franzino e passivo. Isso é facilmente percebido na linguagem do livro, que nos direciona para uma leitura lenta, marcada pelo peso da busca incessante e árdua por algo que faça sentido para o personagem, sem nunca encontrar, obrigatoriamente, um sentido, embora, ao fim da narrativa, a escrita esteja apontada como uma possível saída. Tornar-se escritor pode ser um modo de conviver com a falta do pai e com a impossibilidade de o personagem lidar com seu sentimento de deslocamento diante do mundo, que se descortina à sua frente. Sílvio, ao fim do romance, muda-se de cidade e busca uma função para si.

Origem e paternidade entrelaçam-se, então, nas páginas de Dias perdidos, pois a busca da identidade de Sílvio remete-nos a um longo percurso de incerteza, culpa e conflitos que só cessam, ou recomeçam de maneira diferenciada, quando o personagem se desvencilha de todas as imagens retorcidas que constrói do pai e de todos que o representam, voltando-se para a escrita. É nesse momento que nosso personagem se vê como reflexo desses conflitos e obrigado a livrar-se do pai, para que se torne senhor de si, ainda que 
essa identidade seja pautada na criação de um mundo idealizado na imagem do outro.

A paternidade é decorrente de uma função social. Livrar-se do pai significa encontrar em si a figura da autoridade e do poder. As disputas pelo poder de Sílvio são travadas, inicialmente, com sua mãe Clara, com Diana, sua esposa, e Chico, seu melhor amigo. Mas o ponto crucial dessa disputa dá-se no retorno de Jaques à família. A volta de Jaques representa mais uma tentativa fracassada de paternidade, pois seu regresso traz mais desordem a casa e instaura em Sílvio o sentimento de rancor, dúvidas ainda maiores e a sensação de invasão de seu 'eu' e de seu território, conforme se pode perceber no fragmento abaixo, retirado dos diversos raciocínios do personagem:

Quem dera àquele homem o direito de penetrar assim na sua casa, de se apossar de tudo, de se fechar até no próprio quarto de Clara? [...] Tinha a impressão de que fora roubado nalguma coisa. Seria assim em todas as casas, todos os pais agiriam daquele modo? Neste caso ele não podia deixar de odiar mortalmente os pais. (CARDOSO, 1980, p.144)

Percebe-se, então, que a tentativa de Jaques, que havia ido embora de casa e volta para casa muito depois, já doente e cansado, está fadada ao fracasso. Ele não tenta, obrigatoriamente, ser o patriarca da família, mas, dentro da cultura na qual se insere, tem a representação da função paterna, embora ele não cumpra com seu papel. Dentro da função paterna, cabe àquele que representa o pai manter a casa, colocar ordem, instaurar a lei. No entanto, Jaques chega cansado, envelhecido, sem dinheiro e, juntamente com tudo isso, sem o mínimo poder de instaurar uma lei do pai naquele ambiente no qual vivem, ou viviam até aquele momento, duas mulheres e um menino.

Jaques é visto por todos, mas principalmente pelo filho, como um estranho, alheio à realidade daquela casa. Porém, seu retorno é decisivo para que a relação entre Clara e Sílvio se fortaleça, uma vez que os dois tornam-se cúmplices pelos obscuros sentimentos que nutrem por Jaques. Entretanto, tal aproximação não consegue sanar as consequências trazidas pela falta da função paterna. Jaques retorna a casa como a personificação do fracasso, 
porém não aceita que as razões para seus infortúnios estejam em si mesmo e, por isso, acusa a todos os que o cercam de uma conspiração. Ele retorna para morrer aos cuidados dos seus e traz consigo uma sombra absoluta que se impõe sobre a casa e desperta em seus moradores o sentimento de rancor mesclado ao de culpa.

Essa parte do livro aproxima-nos mais uma vez da relação que o escritor Lúcio Cardoso estabelece com seu pai. Em uma carta que Joaquim Lúcio Cardoso escreve ao filho, ele diz: "A ti e a teus irmãos, confiam Deus a tarefa do meu amparo na ultima ( sic) etapa da vida" (CARDOSO b, s/d, p. 1). O pai de Lúcio Cardoso é, assim como Jaques, um homem que fracassa em todas as suas funções sociais. Note-se como o pai se coloca em um papel que não é o lugar daquele que deve amparar os seus, que deve levar adiante os valores da sociedade, imprimir em seus filhos a lei da cultura, mas, ao contrário, coloca-se em um papel passivo diante dos filhos, a ponto de querer deles o amparo para sua velhice. Essa característica do pai do escritor reflete na construção de personagens de outras obras, pois assim será o personagem de Maleita, que fracassa em sua tentativa de civilizar uma cidade do sertão mineiro; Rogério Palma, que fracassa na criação do filho Inácio, em $O$ enfeitiçado; e assim será Valdo, impossibilitado de cuidar ou de estabelecer a lei para seu filho André, assim como seu irmão, Demétrio, incapaz de ter filhos em Crônica da casa assassinada.

A morte do pai fecha mais um ciclo e Sílvio amadurece cercado pela monotonia e pelo tédio. Sua atenção volta-se, então, para Diana, sua paixão da infância, que retorna a Villa Velha para tratar de uma doença e passa a ser um ponto de referência para o personagem. Porém, assim como todos os referenciais de Sílvio, Diana é, também, a imagem do fracasso. A doença parece ser metaforizada como o insucesso dos personagens de Dias perdidos, pois tanto Jaques quanto Diana - personagens descritos inicialmente como cheios de fulgor, força, beleza e magnetismo - definham em doenças incuráveis que os fazem ver todos os seus sonhos se esvaírem. No caso de Diana, acostumada aos luxos e às modernidades do Rio de Janeiro, o que 
parece ser o principal intensificador de sua doença é a mesquinhez que a pacata Minas Gerais encerra. Esse é mais um dos pontos que nos levam a Lúcio Cardoso, pois Vila Velha "metaforiza as muitas cidadezinhas fechadas de nossas Minas Gerais. Aliás, o amor de Lúcio por Minas Gerais sempre foi mesclado pelo ressentimento e pelo ódio" (BRANDÃO, 2007, p. 37). Assim, o referencial paterno pode ser relacionado também a Minas Gerais, que aparece nos romances cardosianos como uma terra de culpa que ceifa todos os ideais e sonhos de suas personagens.

Assim como Diana e Jaques, Clara é vítima das metáforas patológicas de Lúcio Cardoso, pois desenvolve um tumor terminal repleto de ramificações. $O$ câncer de Clara funciona como uma metáfora perfeita para a realidade tediosa e desesperadora que consome os personagens do romance, sempre predestinados a vidas perdidas que culminam na morte ou no fracasso. Para Sílvio, a única possibilidade de continuidade é a extração completa do mal enraizado. Para isso, ele se separa de Diana, deixando-a livre para seguir seus próprios caminhos e para que, assim como ela, ele possa trilhar os seus. É neste momento que o "parricídio" aparece como propiciador para a criação do escritor e, consequentemente, da autoridade do indivíduo, pois é só a partir do momento em que Sílvio deixa a cidade de Vila Velha, local onde ocorre o romance, que ele poderá se tornar escritor. Essa escrita é vista como uma maneira de se firmar como sujeito, mas só é possível quando o personagem enterra todas as figuras paternas e as torna apenas imagens idealizadas e reconstruídas através da memória.

Sendo assim, torna-se imprescindível a compreensão da morte do pai como nascimento do autor, pai de suas obras. Mesmo ausente, o pai ainda é um regulador, interditor e é essa interdição que introduz o sujeito na cultura, uma vez que é a dominação dos instintos, especialmente os sexuais, que constitui a cultura (cf. FREUD, 1999). Em Totem e tabu, Freud subdivide a função paterna em três: o pai primevo - o mito fundador da cultura -, o pai rival e o pai da castração. Dessa forma, o indivíduo só consegue se formar quando 
se desvincula dessas três figuras, ou seja, quando mata o pai. Tanto para Lúcio Cardoso quanto para Sílvio, a forma de quebrar esses vínculos é a escrita.

Apesar da forte presença, poucas são as dissertações e teses que tratam da questão da paternidade nos romances cardosianos, mas o fato é que a relação que Lúcio Cardoso estabelece com seu pai é um fator determinante em suas obras e, portanto, em sua constituição como escritor. A linguagem dá ao indivíduo o poder de intervenção e de reestruturação, ou seja, ela permite que o indivíduo se torne autor, que ele seja um elemento de autoridade, de pai de sua escrita e um elemento de origem e recriação de sua própria história, uma vez que a literatura, mesmo que ficcional, está intrinsecamente relacionada à vida do escritor, um elemento de origem e recriação de sua própria história.

Assim, o parricídio é metaforizado como principal responsável para a criação do escritor na obra Dias perdidos, pois a escrita é vista como uma maneira de autoafirmação do sujeito, mas só é possível quando o personagem enterra todas as figuras paternas e as torna apenas imagens idealizadas e reconstruídas através da memória. Sendo assim, reafirmamos, torna-se de suma importância a compreensão da morte do pai como nascimento do autor, pai de suas obras, o que, no caso de Lúcio Cardoso, é perceptível, pois sua escrita recria a si e ao pai, cometendo, nas várias transfigurações paternas, seu assassinato.

\section{Referências bibliográficas}

AYALA, Walmir. Biografia de Lúcio Cardoso. Acervo de Lúcio Cardoso, Fundação Casa de Rui Barbosa, código LC 06 pit, s/d.

BANDEIRA, Manuel. Carta de Manuel Bandeira; Petrópolis, 17 de janeiro de 1935. Acervo de Lúcio Cardoso, Fundação Casa de Rui Barbosa, código LC 24 cp.

BRANDÃO, Ruth Silviano. Lúcio Cardoso: príncipe, mas esfarrapado. Ipotesi. Juiz de Fora: UFJF, v. 11, jan/ jun 2007. p. 31-38. 
BRANDÃO, Ruth Silviano. A vida escrita. Rio de Janeiro: 7 Letras/Belo Horizonte: Poslit, 2006.

BRANDÃO, Ruth Silviano (Org.). Lúcio Cardoso - a travessia da escrita. Belo Horizonte: UFMG, 1998.

CARDOSO, Joaquim Lúcio. Carta do pai de Lúcio Cardoso a ele, s/d. Acervo de Lúcio Cardoso, Fundação Casa de Rui Barbosa, código LC 05 cf, 1 fl.

CARDOSO, Lúcio. Crônica da casa assassinada. São Paulo: Ediouro, 1977.

CARDOSO, Lúcio. Dias perdidos. Rio de Janeiro: Nova Fronteira, 1980.

CARDOSO, Lúcio. Diário do Terror. In: SEFFRIN, André. Uma gigantesca espiral colorida. In: CARDOSO, Lúcio. Crônica da casa assassinada; 50 anos de publicação. Rio de Janeiro: Civilização Brasileira, 2009.

CARDOSO, Lúcio. Artigo incompleto sobre William Faulkner. Acervo de Lúcio Cardoso, código LC 55 pi, s/d, 1 fl.

CARELLI, M. Corcel de fogo: vida e obra de Lúcio Cardoso (1912-1968). Trad. Júlio Castañon Guimarães. Rio de Janeiro: Guanabara, 1988.

FREUD, Sigmund. Totem e tabu. Trad. Órizon Carneiro Muniz. Rio de Janeiro: Imago, 1999.

PESSOA, José Eduardo Marco. O pai ausente - leitura de Por onde andou meu coração, de Maria Helena Cardoso, e do romance Dias perdidos, de Lúcio Cardoso. In: BRANDÃO, Ruth Silviano (Org.). Lúcio Cardoso - a travessia da escrita. Belo Horizonte: UFMG, 1998. p. 46-67.

SABINO, Fernando. Carta a Lúcio Cardoso; Juiz de fora, 1/12/1943. Acervo de Lúcio Cardoso, código LC 191 cp, 3 fls.

SANTOS, Cássia dos. Polêmica e controvérsia em Lúcio Cardoso. Campinas: Mercado das Letras, 2001.

VILELA, Andréa de Paula Xavier. Lúcio Cardoso: o traçado de uma vida. 2007. 204 f. Tese (Doutorado em Estudos Literários) - Faculdade de Letras, Universidade Federal de Minas Gerais, Belo Horizonte, 2007.

\footnotetext{
' Este artigo é resultado de uma bolsa de pesquisa de iniciação científica concedida pela FAPEMIG e faz parte do Projeto Escrever o pai é escrever-se uma análise da
} 
ficção de Lúcio Cardoso, coordenado por Fábio Figueiredo Camargo e fomentado pela FAPEMIG entre os anos de 2010 a 2012.

i O documentário (19 minutos, 1993, RJ) foi dirigido e escrito por Eliane Terra e Karla Holanda. Encontra-se disponível em www.emfocomultimidia.com.br. Elenco: Buza Ferraz. Depoimentos de: Rachel de Queiroz, Antônio Carlos Villaça, Ledo Ivo, Nelson Dantas, entre outros.

iii Muitos dos textos aqui citados são documentos constantes do Acervo de Lúcio Cardoso, contido na Fundação Casa de Rui Barbosa, no Rio de Janeiro. Agradecemos ao Acervo e a seus funcionários o acesso a esses documentos que serão citados conforme o manual da ABNT no corpo do texto e, embora não tenham sido publicados, serão citados nas referências bibliográficas conforme seu arquivamento no Acervo do escritor.

iv No entanto, vale ressaltar que Dias Perdidos é um dos romances iniciais de Lúcio Cardoso, que, criador de uma vasta obra, viria a ser reconhecido principalmente pelo romance Crônica da casa Assassinada, de 1959.

Artigo recebido em: 30 de abril de 2013

Artigo aprovado em: 30 de maio de 2013

\section{Sobre a autora:}

Graduada em Letras pela Universidade Estadual de Montes Claros (2012).

\section{Sobre o autor:}

Doutor em Literaturas de Língua Portuguesa pela Pontifícia Universidade Católica de Minas Gerais (2007). 